(1)

CrossMark

\title{
Urgent need of a management plan for survivors of COVID-19
}

To the Editor:

Acute exacerbations of COPD (AECOPD) or "COPD crises" [1], are crucial events in the natural course of COPD. Although they can occur at any severity stage, their impact increases as patients develop more severe airflow limitation.

Several studies have demonstrated that the occurrence of COPD exacerbations increases the risk of myocardial infarction and stroke [2], all cause [3,4] and cardiovascular mortality [5], in the post exacerbation period, particularly in AECOPD with associated pneumonia [6]. This was best demonstrated by KunISAKI et al. [7] in a pre-specified analysis of the data from the SUMMIT trial of over 16 thousand patients with moderate COPD and heightened cardiovascular risk. The authors found that the hazard ratio for cardiovascular events was increased, particularly in the first 30 days after the exacerbations (HR 3.8, 95\% CI 2.7-5.5). The risk increased more than two-fold if the exacerbations led to a hospitalisation; in this case, the hazard ratio reached 9.9 (95\% CI 6.6-14.9). This study was important because all deaths were analysed by a clinical end-point committee. There was an unusually high number of cardiovascular events occurring after the exacerbations, suggesting some vascular dysfunction leading to myocardial infarction, stroke and pulmonary embolism.

This scenario appears to be similar to that reported to occur following hospitalised pneumonias, particularly in the elderly [8-10].

The current coronavirus disease 2019 (COVID-19) pandemic affects primarily adults and particularly those affected by one or more chronic diseases [11]. Because most cases of severe COVID-19 are due to pneumonia associated with respiratory failure [11, 12], it is likely that, similar, to patients with exacerbations of COPD and/or community acquired pneumonia, the survivors of COVID will be at high risk of cardiovascular events and mortality following the acute phase of the disease. We would like to call attention to this vulnerable period, and recommend that patients be closely followed with a management plan that pays special attention to the prompt recognition of cardiovascular complications, especially in the 30 days following the resolution of the acute phase of the event. It would be a pity that those survivors of COVID-19 pneumonia, would then succumb from a relatively preventable consequence.

@ERSpublications

Survivors of COVID-19 may be at increased risk of cardiovascular morbidity and mortality and should be carefully monitored https://bit.ly/2UhVjoy

Cite this article as: Celli B, Fabbri LM. Urgent need of a management plan for survivors of COVID-19. Eur Respir J 2020; 55: 2000764 [https://doi.org/10.1183/13993003.00764-2020].

Bartolome Celli $\odot^{1}$ and Leonardo M. Fabbri $\oplus^{2}$

${ }^{1}$ Pulmonary and Critical Care Division, Brigham and Women's Hospital, Wellesley, MA, USA. ${ }^{2}$ University of Ferrara, Ferrara, Italy.

Correspondence: Leonardo M. Fabbri, Viale Giuseppe Verdi 59, 41121 Modena, Italy.

E-mail: leonardo.fabbri20@gmail.com

Received: 19 March 2020 | Accepted: 19 March 2020

Conflict of interest: B. Celli reports personal fees and research facilities from AstraZeneca, personal fees for consultancy from GlaxoSmithKline, Boehringer Ingelheim, Novartis, Sanofi Aventis and Menarini outside the submitted work. L.M. Fabbri reports personal fees and non-financial support from AstraZeneca, Chiesi, GSK, Novartis, Boehringer Ingelheim and Zambon, personal fees from Lusofarmaco, outside the submitted work.

\section{References}

1 Bafadhel M, Criner G, Dransfield MT, et al. Exacerbations of chronic obstructive pulmonary disease: time to rename. Lancet Respir Med 2020; 8: 133-135.

2 Donaldson GC, Hurst JR, Smith CJ, et al. Increased risk of myocardial infarction and stroke following exacerbation of COPD. Chest 2010; 137: 1091-1097. 
3 Mullerova H, Maselli DJ, Locantore N, et al. Hospitalized exacerbations of COPD: risk factors and outcomes in the ECLIPSE cohort. Chest 2015; 147: 999-1007.

4 Hartl S, Lopez-Campos JL, Pozo-Rodriguez F, et al. Risk of death and readmission of hospital-admitted COPD exacerbations: European COPD Audit. Eur Respir J 2016; 47: 113-121.

5 Wang M, Pei-Ying Lin E, Huang L, et al. Mortality of cardiovascular events in COPD patients with preceding hospitalized acute exacerbation. Chest 2020; in press [https://doi.org/10.1016/j.chest.2020.02.046].

6 Shin B, Kim SH, Yong SJ, et al. Early readmission and mortality in acute exacerbation of chronic obstructive pulmonary disease with community-acquired pneumonia. Chron Respir Dis 2019; 16: 1479972318809480

7 Kunisaki KM, Dransfield MT, Anderson JA, et al. Exacerbations of chronic obstructive pulmonary disease and cardiac events. A post hoc cohort analysis from the SUMMIT randomized clinical trial. Am J Respir Crit Care Med 2018; 198: 51-57.

8 Cilloniz C, Ferrer M, Liapikou A, et al. Acute respiratory distress syndrome in mechanically ventilated patients with community-acquired pneumonia. EurRespir J 2018; 51: 1702215.

9 Jain S, Self WH, Wunderink RG, et al. Community-acquired pneumonia requiring hospitalization among U.S. adults. N EnglJ Med 2015; 373: 415-427.

10 Yousufuddin M, Shultz J, Doyle T, et al. Incremental risk of long-term mortality with increased burden of comorbidity in hospitalized patients with pneumonia. Eur J Intern Med 2018; 55: 23-27.

11 Wang $\mathrm{D}, \mathrm{Hu} \mathrm{B}, \mathrm{Hu} \mathrm{C}$, et al. Clinical characteristics of 138 hospitalized patients with 2019 novel coronavirus-infected pneumonia in Wuhan, China. JAMA 2020; in press [https://doi.org/10.1001/jama.2020.1585].

$12 \mathrm{Wu}$ C, Chen X, Cai Y, et al. Risk factors associated with acute respiratory distress syndrome and death in patients with coronavirus disease 2019 pneumonia in Wuhan, China. JAMA Intern Med 2020; in press [https://doi.org/ 10.1001/jamainternmed.2020.0994]. 